\title{
Pro-ecological packaging materials based on polyhydroxybutyrate (PHB)
}

\author{
Malgorzata Latos ${ }^{1, *}$, and Anna Masek ${ }^{1}$ \\ ${ }^{1}$ Lodz University of Technology, Institute of Polymer and Dye Technology, Faculty of Chemistry, \\ 90-924 Lodz, ul. Stefanowskiego 12/16, Poland
}

\begin{abstract}
Polymers are common used in everyday life. For economic reasons and specific properties, they replace traditional materials such as glass, wood or paper. The use of polymeric materials generates waste, whose disposal is difficult. Legislation and pressures on the use of proecological materials have increased interest in biodegradable polymers. Such polymers are polyhydroxyalkanoates. It is also important to use ecofriendly processing additives added to polymeric materials. The most commonly used anti - aging substances are triazine and hindered amine HALS (Hindered Amine Light Stabilizers). Most of these substances are considered to be toxic. Therefore, application of natural compounds in polymers is an interesting alternative. Polyphenols of plant origin are compounds that exhibit high reducing properties in oxidation processes. These compounds should protect polymeric materials against negative influence of environmental factors.
\end{abstract}

\section{Introduction}

The problem of storage and disposal of polymer waste, the pressure to replace traditional plastics with environmentally friendly materials and legal provisions, have resulted in the need to search for materials with biodegradable properties. Biodegradable polymers are thermoplastics which can be processed by means of the same methods as synthetic polymers. They are characterized by good physico-mechanical and physico-chemical properties. The lifetime of these materials can be controlled by modifying the structure of the polymer chain and can range from several weeks to several years. In addition to the polymer structure, other factors influence the biodegradation, such as the average molecular weight of the polymer, the presence of unsaturated bonds, the shape of the finished product, environmental conditions, the type of active microorganisms and other $[1,2]$. Due to their origin, biodegradable polymers are divided into two groups: obtained from petrochemical raw materials and obtained from renewable raw materials. The second group is often called double-green polymers because they are both biodegradable and derived from renewable raw materials $[3,4]$.

A significant group of biodegradable polymeric materials are poly (hydroxyalkanoates) PHA. They are characterized by excellent application properties, because they are

\footnotetext{
* Corresponding author: malgorzata.latos@edu.p.lodz.pl
} 
biocompatible, non-toxic, and are subject to enzymatic degradation [3]. Poly (hydroxybutyrate) (PHB) is a representative of this group. PHB is a natural aliphatic polyester of microbial origin. The polymer is produced inside various microorganisms: Bacillus, Nocardia, Pseudomonas, Alcaligenes, Azotobacter, Rhizobium [5, 6].

In the poly (hydroxyalkanoate) group, two subgroups are distinguished. The first

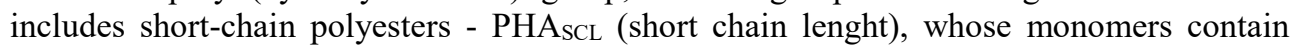
from 4 to 5 carbon atoms in their structure. The second subgroup is medium-chain PHA (PHA $\mathrm{PCL}_{\mathrm{MC}}$ ), the monomers of which contain 6-16 carbon atoms. Different physical properties result from the different construction of PHASCL and PHAMCL polyesters.

Poly (hydroxybutyrate) (PHB), due to similar mechanical properties, is compared to polypropylene. The polymer, however, is more crystalline and consequently has greater stiffness and brittleness. Decreasing the degree of crystallinity of PHB and improving physical properties are achieved by obtaining copolymers of hydroxybutyrate and hydroxyvalerate $[5,6]$.

An important group of processing additives are stabilizers, added to polymers to protect them from aging. As stabilizers for polymers are used benzophenones, benzotriazoles, triazines (organic UV absorbers ), phosphates, aromatic and aliphatic amines, cyclic metal chelates and hindered amines HALS (Hindered Amine Light Stabilize). A serious drawback of some stabilizers is the negative impact on human life. These substances can increase the risk of many diseases. In addition, some of them are considered to be toxic for the environment [7-11].

Designing additives for polymers, including stabilizers, is closely related to the fulfillment of specific economic and ecological requirements. The compounds used should be effective, cheap and environmentally friendly. These conditions are met by polyphenols of vegetable origin, which show high antioxidant activity [8].

\section{Materials and methods}

\subsection{Object of research}

Poly(hydroxybutyrate) PHB (Melting point $18 \mathrm{~g} / 10 \mathrm{~min}\left(170^{\circ} \mathrm{C} / 2.16 \mathrm{~kg}\right) \mathrm{SimagChem}$, China) was used as a research object. As stabilizers were used rutin trihydrate $(\geq 90 \%$, $\mathrm{Mw}=664.56 \mathrm{~g} / \mathrm{mol}$, Sigma Aldrich, China) - a natural antioxidant, and Tinuvin $234(\mathrm{Mw}=448 \mathrm{~g} / \mathrm{mol}$, Ciba, Italy) - a commercially used UV absorber (Fig. 1). The composition of the samples is summarized in Table 1.

Table 1. Composition of samples.

\begin{tabular}{|c|c|c|c|}
\hline \multirow{2}{*}{ Component } & Sample 1 & Sample 2 & Sample 3 \\
\cline { 2 - 4 } & \multicolumn{3}{|c|}{ parts by weight } \\
\hline PHB & 100 & 100 & 100 \\
\hline $\begin{array}{c}\text { Rutin } \\
\mathbf{x} 3 \mathbf{H}_{2} \mathbf{O}\end{array}$ & - & 1 & - \\
\hline $\begin{array}{c}\text { Tinuvin 234 } \\
\text { Pind }\end{array}$ & - & - & 1 \\
\hline
\end{tabular}

Sample 1 - PHB; Sample 2 - PHB/Rutin x $3 \mathrm{H}_{2} \mathrm{O}$; Sample 3 - PHB/Tinuvin 234 
The dried granulate was mixed with antioxidants and extruded using a laboratory extruder. The temperature of the working chamber of the extruder was $160^{\circ} \mathrm{C}$.<smiles>C[C@@H](O)CC(=O)OCC(C)(C)CCCC(=O)O[TlH]</smiles>

Poly(hydroxybutyrate) PHB<smiles>CC1CC(OCC2OC(Oc3c(-c4ccc(O)c(O)c4)oc4cc(O)cc(O)c4c3=O)C(O)C(O)C2O)C(O)C(O)C1O</smiles>

Rutin trihydrate

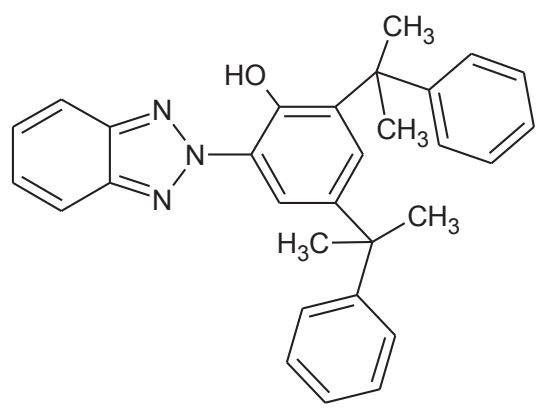

Tinuvin 234

Fig. 1. Used chemicals (polymer PHB and antioxidants: rutin trihydrate and Tinuvin 234).

\subsection{Measurement methods}

\section{UV aging}

The UV aging was performed using a UV 2000 apparatus from Atlas (Chicago, IL, USA). The measurement was performed for $168 \mathrm{~h}$ (7 days) and consisted of two alternately repeating segments with the following parameters: daily segment (UVA radiation intensity $E=0.7 \mathrm{~W} / \mathrm{m}^{2}, \lambda=340 \mathrm{~nm}$, temperature $60^{\circ} \mathrm{C}$, duration $8 \mathrm{~h}$ ), night segment (no $\mathrm{UV}$ radiation, temperature $50^{\circ} \mathrm{C}$, duration $4 \mathrm{~h}$ ).

\section{Vicat softening temperature}

The Vicat softening temperature test was done using a D-Vicat.HDT/3/400FA apparatus, according to the PN-EN ISO 306 standard. The Vicat softening temperature is the temperature at which a hardened steel needle with a circular cross-section of $1 \mathrm{~mm}^{2}$ penetrates into the test sample, with a standard load of $10 \mathrm{~N}$ to a depth of $1 \mathrm{~mm}$. The rate of temperature increase during the test was $120^{\circ} \mathrm{C} / \mathrm{h}$.

\section{Surface free energy}

The surface free energy of the polymeric materials $(\gamma s)$ was determined on the basis of measured contact angles. Measurements of the contact angles were made for liquids: distilled water, diiodomethane, glycerol and ethylene glycol, which are characterized by different polarity $[12,13]$.

\section{Change of colour}

The colour measurement was performed according to PN-EN ISO 105-J01, to determine the colour change of samples after UV aging. The measurements were carried out using a Konica Minolta CM-3600d spectrophotometer. The colour change test is based on the conversion of light reflected from the surface of the test sample to the colour that 
is taken by the photoreceptors in the human eye. The result is the colour described in the CIE-Lab space and the coordinates that allow to determine the colour in the system of three coordinates: $\mathrm{L}$, a and $\mathrm{b}$, where:

- $L$ - lightness parameter

The maximum value for $\mathrm{L}$ is 100 , which represents a perfect reflecting diffuser. The minimum value for $\mathrm{L}$ is zero, which represents the colour black.

- $a$ - the axis of red - green

- $b$ - the axis of yellow - blue

The $\mathrm{a}$ and $\mathrm{b}$ axes have no specific numerical limits.

The change of colour $\Delta \mathrm{E}$ was calculated as follows (1):

$$
\Delta \mathrm{E}=\sqrt{\left(\Delta a^{2}\right)+\left(\Delta b^{2}\right)+\left(\Delta L^{2}\right)}
$$

Together with the characteristic values obtained reflection spectra of samples depending on the wavelength.

\section{Results}

The softening temperature is usually given for amorphous or partially crystalline and partly amorphous materials having a mixed microstructure. Amorphous and amorphouscrystalline materials do not usually have a melting point, because the process of their transition from solid to high-viscous fluid occurs gradually and does not consist in a simple conversion of the crystal into a liquid. In the case of thermoplastics, it is not possible to determine a precise melting point that would accurately indicate the transition from solid to liquid. As the temperature rises, the material softens slowly. The addition of antioxidants (natural and synthetic) significantly changes the softening temperature compared to the reference sample (Fig. 2). The UV aging caused slight changes in the Vicat softening temperature of the PHB sample, while in the case of samples with antioxidants, these changes are marked. Rutin trihydrate and Tinuvin 234 affect the thermal properties of materials, understood as functional properties.

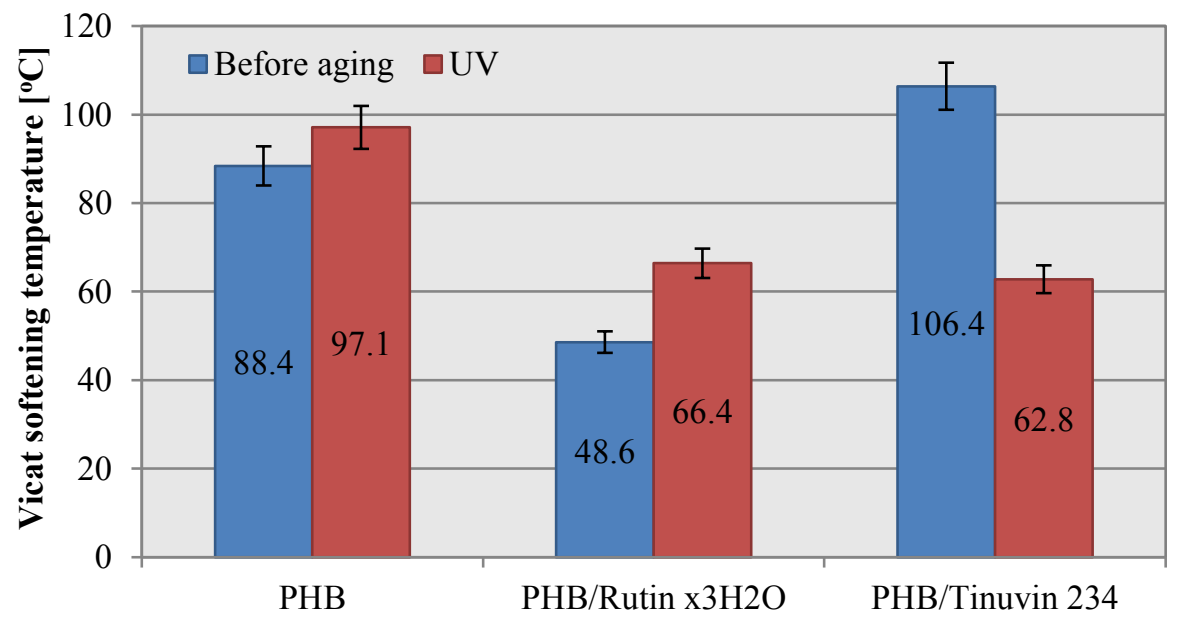

Fig. 2. The change of Vicat softening temperature after UV aging.

Figure 3 shows the change in surface free energy under the influence of simulated UV aging. Surface free energy is one of the thermodynamic functions describing the state 
of equilibrium between atoms in the surface layer of materials. It is a characteristic quantity, proper to every physical body. The addition of antioxidants caused an increase in the surface free energy of materials (PHB - $65.1 \mathrm{~mJ} / \mathrm{m}^{2} ; \mathrm{PHB} /$ Rutin $\times 3 \mathrm{H}_{2} \mathrm{O}-$ $69.3 \mathrm{~mJ} / \mathrm{m}^{2} ;$ PHB/Tinuvin $234-79.6 \mathrm{~mJ} / \mathrm{m}^{2}$ ). After UV aging, the surface free energy of all samples were decreased. Smaller surface free energy values indicate less adhesive properties.

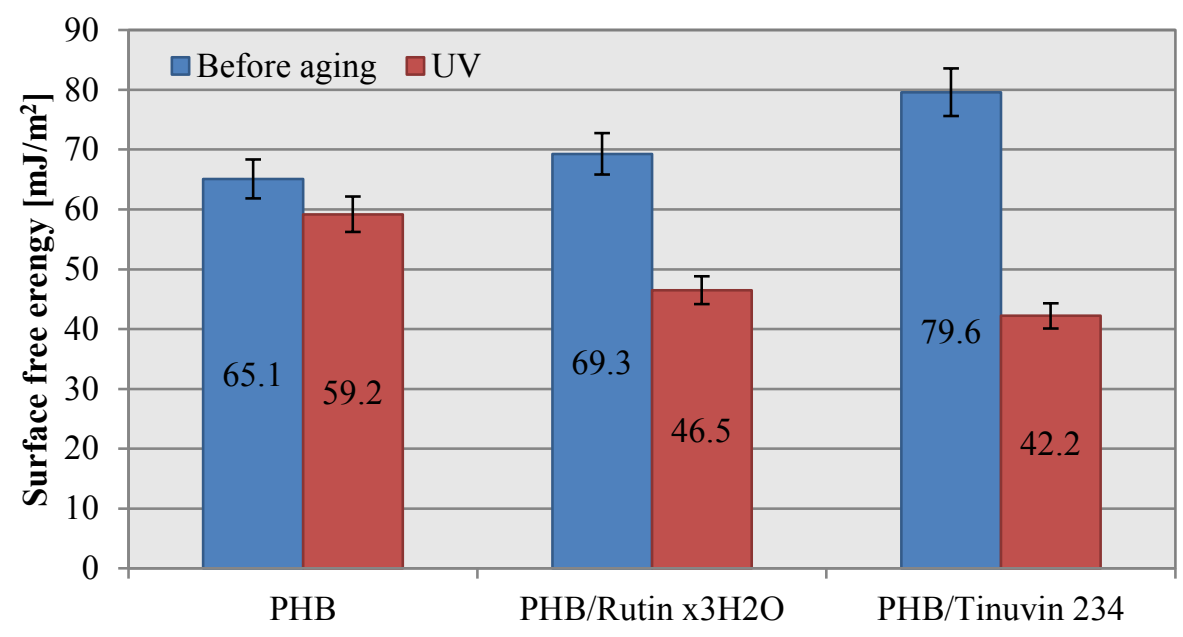

Fig. 3. The change of surface free energy of PHB and PHB with antioxidants after UV aging.

The change of the colour of the materials is shown on figure 4. The UV aging the most affected colour of the sample PHB/Rutin trihydrate. Statistically, when $\Delta \mathrm{E}>5$ colours are seen as completely different. For these samples, the colours of PHB standard and $\mathrm{PHB} /$ Rutin $\times 3 \mathrm{H}_{2} \mathrm{O}$ have changed significantly, and the observer sees two different colours. The colour change of the sample with Tinuvin 234 is in the range $3.5<\Delta \mathrm{E}<5$, which means that the observer notices a clear difference between the colours of the aged and unaged samples. Figure 5 shows the reflection spectra of the samples tested. For materials PHB and PHB/Rutin trihydrate, the colour shift towards negative values, PHB sample on the blue axis, and sample with natural antioxidant - on the red axis were found. Under the influence of UV, sample with commercially used UV absorber, showed its colour shift towards positive values on the blue axis.

The largest change of the colour of the sample PHB/Rutin trihydrate after aging is well shown in the picture (Fig. 6). 


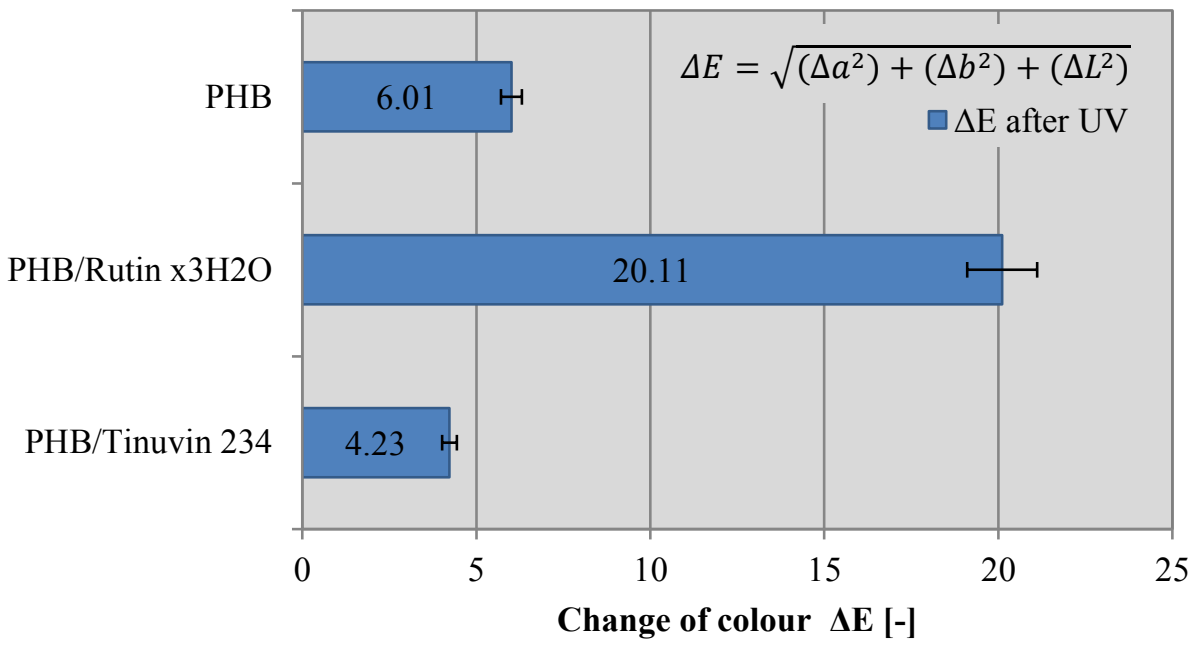

Fig. 4. The change of colour $(\Delta \mathrm{E})$ after UV aging.

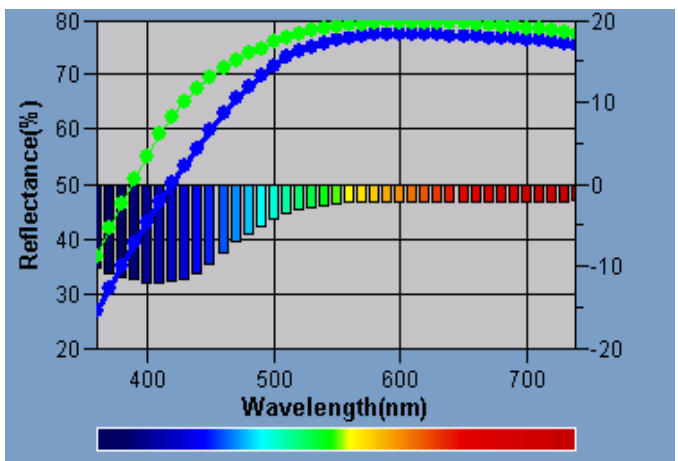

PHB

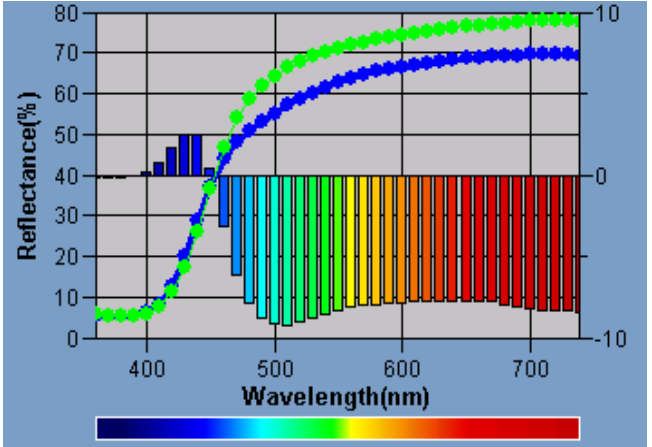

PHB/Rutin $\times 3 \mathrm{H}_{2} \mathrm{O}$

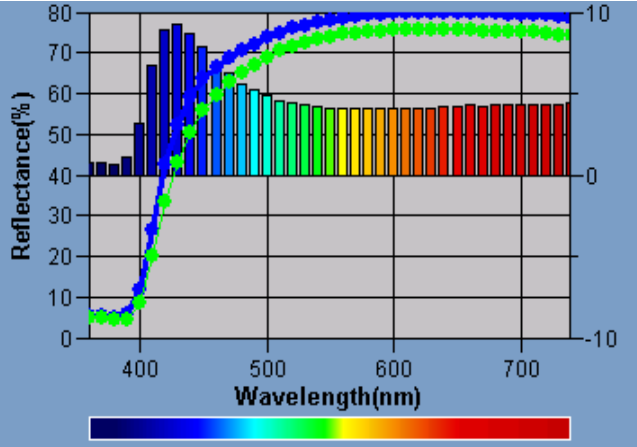

PHB/Tinuvin 234

Fig. 5. The reflection spectra of samples PHB and PHB with antioxidants. 


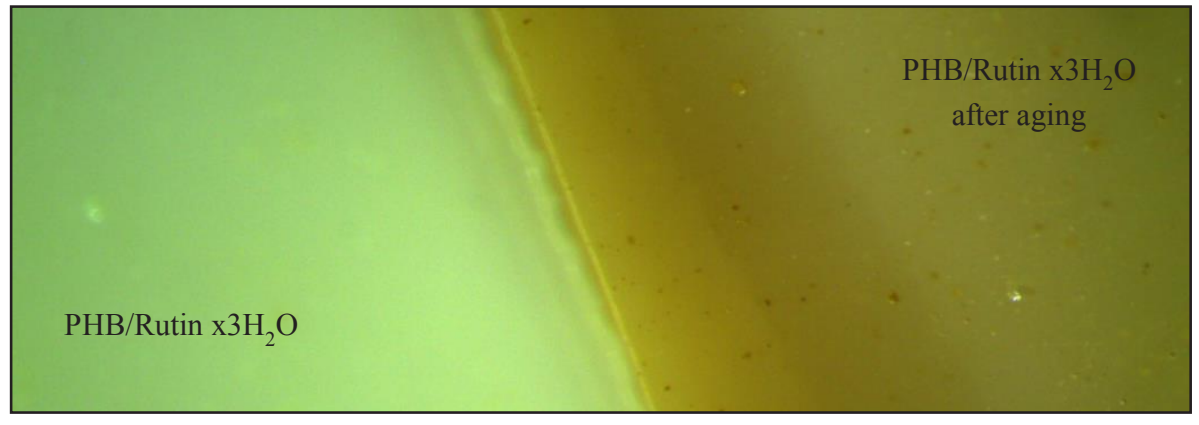

Fig. 6. Photograph of sample $\mathrm{PHB} / \mathrm{Rutin} \times 3 \mathrm{H}_{2} \mathrm{O}$ before and after aging.

\section{Conclusions}

The beneficial and specific properties of biodegradable polyesters from the group of poly (hydroxyalkanoates), including poly(hydroxybutyrate), allow the use of these polymers as easier to dispose of packaging materials. The addition of antioxidants, both natural and synthetic, modifies the processing properties of PHB (Vicat softening temperature) and causes adhesive properties (surface free energy) changes. Material with plant-derived antioxidant from e.g. Tartary buckwheat, black chokeberry and black elder (rutin trihydrate), showed the greatest colour change caused by UV aging.

Changing the colour of such material can be an indicator of aging time. This dependence can be applied in the packaging industry, where a change of the colour of the packaging would indicate the freshness of the product and its storage time.

Packaging materials based on PHB with natural antioxidants seem to be a good alternative to the currently used packaging materials, because they are environmentally friendly and harmless to the health of consumers. The polymer used is completely biodegradable and commercial antioxidants are replaced by substances of plant origin.

This study was supported by the National Centre for Research and Development (NCBR) project: LIDER/32/0139/L-7/15/NCBR/2016.

\section{References}

1. Z. Florjańczyk, M. Dębski, E. Chwojnowska, K. Łokaj, J. Ostrowska, Polimery 10, 609-694 (2009)

2. R. Malinowski, Teka Kom. Bud. Ekspl. Masz. Elektrotech. Bud. - OL PAN, 103-106 (2008)

3. J. Gołębiewski, E. Gibas, R. Malinowski, Polimery 53, 11-12, 799-807 (2008)

4. P. Bordes, E. Pollet, L. Avérous, Prog Polym Sci. 34, 125-155 (2009)

5. R. Smith, Biodegradable Polymers for Industrial Applications (Woodhead Publishing Limited, 2005)

6. J.F. Rabek, Współczesna wiedza o polimerach (PWN, Warszawa, 2008)

7. C.R. Thompson, J.C. Moore, S.F. Saal, H.S. Swan, Philos. Trans. R. Soc. B 364, 2153-2166 (2009)

8. A. Masek, Polymer. 7, 6, 1125-1144 (2015) 
9. A. Masek, E. Chrzescijanska, M. Zaborski, M. Piotrowska, Compt. Rendus Chim. 17, 1116-1127 (2014)

10. A. Masek, M. Zaborski, E. Chrześciajańska, Compt. Rendus Chim. 16, 990-996 (2013)

11. A. Masek, M. Zaborski, A. Kosmalska, Compt. Rendus Chim. 14, 483-488 (2011)

12. R. Rogowska, Problemy eksploatacji 1, 85-100 (2013)

13. A. Rudawska, S. Zajchowski, Polimery 52, 6, 453-455 (2007) 